\title{
MEMBRANE FOULING IN CANE-SUGAR SYRUP FILTRATION
}

\section{Ali K. Abdel-Rahman}

Associate Professor, Department of Mechanical Engineering, Faculty of Engineering, Assiut University, Assiut 71516, EGYPT

E-mail: nada_ali54@yahoo.com

\section{Abdel-Aziz A. Abbara}

Department of Food Engineering, Al-Baath University, Homs, Syria

\section{Mohamed R. Bayoumi}

Vice President of Assiut University, Assiut, Egypt

(Received September 10, 2008 Accepted October 25, 2008)

\begin{abstract}
Crossflow microfiltration $(M F)$ and ultrafiltration (UF) experiments of limed mixed juice to $\mathrm{pH}$ of 7.5 were carried out in plate and frame module employing polysulphone membranes. The experimental study was carried out to examine the effects of membrane molecular weight (MWCO) and the transmembrane pressure (TMP) on the membrane fouling characteristics and flux decline behavior. A comparative analysis using one $M F$ membrane (GRMO.1PP MF) and one UF membrane (GR4OPP UF) was done at different TMP (viz. 1.0, 1.5 and 2.0 bar). Three theoretical models (viz. cake filtration model, internal pore blocking model, and complete pore blocking model) were used to predict the membrane resistances and permeate flux. The models were used further to help in the analysis and to isolate a suitable membrane among the studied one with respect to flux and resistance.

It was noticed that in all cases the membrane fouling was the highest at the first period of operation. Study of the mechanisms responsible for flux decline in MF and UF of limed mixed juice suggested that the membrane fouling is in good correlation with the cake filtration model and the pore narrowing (internal pore blocking) model for both the GRMO.1PP MF and GR4OPP UF.
\end{abstract}

KEYWORDS: Membrane fouling, Mixed juice, Microfiltration, Ultrafiltration, Transmembrane pressure.

\section{INTRODUCTION}

The production of raw sugar for export and for domestic production of refined sugar is a very important industry for the Egyptian agro-industry sector. The conventional process of raw sugar production uses significant amounts of lime, and produces large quantities of waste product called lime mud. Although, the conventional production of white sugar from either cane or beet has been well established over the years, the sugar industry has to accommodate itself with the new environmental regulations and to upgrade the quality of sugar with optimizing the production cost using advanced technologies. 


\section{NOMENCLATURE}

Alphabetic Symbols

A membrane area $\left(\mathrm{m}^{2}\right)$

$A_{o}$ total membrane area $\left(\mathrm{m}^{2}\right)$

$c_{m}$ rejected particle concentration at membrane $\left(\mathrm{kg} / \mathrm{m}^{3}\right)$

$C_{a}$ dimensionless parameter in Eq. (5)

$f_{c}$ fouling rate constant

$J$ flux $(\mathrm{m} / \mathrm{s})$

$J_{2}$ permeate flux at the onset of quasisteady state operation $\left(\mathrm{L} / \mathrm{m}^{2} . \mathrm{s}\right)$

$J_{m}$ permeate mass flux $\left(\mathrm{kg} / \mathrm{m}^{2} . \mathrm{s}\right)$

$J_{o}$ initial permeate flux $\mathrm{m} / \mathrm{s}$

$J_{w}$ permeate flux $\left(\mathrm{L} / \mathrm{m}^{2} . h\right) .1 \mathrm{~L} / \mathrm{m}^{2} \cdot \mathrm{h}=$ $2.778 \times 10^{-7} \mathrm{~m} / \mathrm{s}$

$L_{m}$ membrane thickness (m)

$N$ total numbers of pores in the membrane

$Q_{f}$ permeate flow rate $\left(\mathrm{m}^{3} / \mathrm{s}\right)$

$Q_{o}$ initial permeate flow rate $\left(\mathrm{m}^{3} / \mathrm{s}\right)$

$r$ corrélation coefficient

$r_{p}$ membrane pore radius (m)

$r_{p o}$ initial membrane pore radius $(\mathrm{m})$

$R_{a}$ adsorption resistance $\left(\mathrm{m}^{-1}\right)$

$R_{c}$ cake layer resistance $\left(\mathrm{m}^{-1}\right)$

$R_{c c}$ membrane resistance due to compression of the cake layer $\left(\mathrm{m}^{-1}\right)$
$R_{c p}$ concentration polarization resistance $\left(\mathrm{m}^{-1}\right)$

$R_{f}$ Resistance due to the fouling $\left(\mathrm{m}^{-1}\right)$

$R_{m}$ initial membrane resistance $\left(\mathrm{m}^{-1}\right)$

$R_{p}$ membrane resistance due to blocking of the membrane pores $\left(\mathrm{m}^{-1}\right)$

$R_{t}$ total membrane resistance $\left(\mathrm{m}^{-1}\right)$

$t$ time (s)

$T$ temperature $\left({ }^{\circ} \mathrm{C}\right)$

$V_{f}$ permeate volume $\left(\mathrm{m}^{3}\right)$

$V_{p}$ initial total pore volume $\left(\mathrm{m}^{3}\right)$

$\Delta P$ transmembrane pressure (bar), 1 bar $=10^{5} \mathrm{~Pa}$

$\alpha_{c}$ cake specific resistance per unit mass $(\mathrm{m} / \mathrm{kg})$

$\alpha_{o} \quad$ Slope of the $R_{t}$ evolution curve at the beginning $\left(\mathrm{m}^{-1} \cdot \mathrm{min}^{-1}\right)$

$\alpha_{s} \quad$ slope of the $R_{t}$ curve during the pseudo-steady state phase $\left(\mathrm{m}^{-1} \mathrm{~min}^{-1}\right)$

\section{Greek Symbols}

$\mu$ dynamic viscosity of fluid ( $\mathrm{Pa} . \mathrm{s}$ )

$\alpha_{f}$ fouling rate $\left(\mathrm{m}^{-1} \cdot \mathrm{s}^{-1}\right)$

$\sigma$ parameter characterizing plugging potential of suspension $\left(\mathrm{m}^{-1}\right)$

Membrane separation is one of such technologies that will compete favorably for reducing energy usage, reducing or eliminating chemical clarification and improve final product quality [1]. The purification of sugarcane juice by membrane filtration promises a significant improvement in the sugar quality and yield [2]. In a review which dealt with the application of membrane filtration systems within the beet and cane sugar industry, Madsen et al. [3] suggested that it should be possible to introduce membrane filtration as a unit operation in the sugar industry.

One of the major obstacles which hinder more widespread application of membrane filtration is that the flux declines with time termed as 'membrane fouling' [4]. Flux decline in membrane filtration is a result of the increase of the membrane resistance and the development of another resistance layer, which can be elucidated in terms of pore blockage and cake formation, respectively. The pore blocking increases the membrane resistance while the cake formation creates an additional layer of resistance to the permeate flow. In this sense, pore blocking and cake formation can be considered as two essential mechanisms for membrane fouling. Other factors, such as solute adsorption, particle deposition within the membrane pores, and characteristics change of the cake layer, can affect membrane fouling through enhancement or 
modification of either or both of these two essential mechanisms. The development of a concentration polarization (CP) layer can also add another layer of resistance.

The early work on membrane fouling theories includes the development of the pore blocking and cake formation models [5]. Song [4] has developed a mathematical model to describe the dynamic process of membrane fouling and provided a closedform solution of his model. The fouling process under different conditions was simulated by the newly developed model. His study showed that there are two essential mechanisms for membrane fouling in crossflow UF and MF, namely, pore blocking which is responsible for the initial sharp drop from the flux of pure water filtration, and cake formation which is the cause of long-term gradual flux decline.

Huang and Morrissey [6] have conducted experimental studies to investigate the development of membrane fouling in the microfiltration of protein solutions. Their results showed that the initial membrane fouling process could be modeled by the standard pore blocking law, and the development of fouling continued with a continuous process of cake formation. Wang and Song [7] have compared the theory of fouling dynamics in crossflow membrane filtration with ultrafiltration experiments using suspensions of silica colloids. They have experimentally verified that colloidal fouling in crossflow filtration is a dynamics process from non-equilibrium to equilibrium and that the steady state flux is the limiting flux.

Chen et al. [8] have developed a predictive model for simulating the development of membrane fouling with time in full-scale RO processes. The results of the simulation studies demonstrated that a full-scale RO system could maintain a constant average permeate flux for a period of time even though fouling development had occurred right from the start of operation.

Mohammadi et al. [9] has conducted studies to investigate membrane fouling in Ultrafiltration (UF) of emulsions and suspensions. They have found that development of membrane fouling is a dynamic process of two distinctive stages. Pore blocking is dominant resistance at initial period of UF and cake resistance begins to dominate following the initial pore blocking. The results show that cake layer resistance increases with increasing feed concentration and transmembrane pressure.

In the present study crossflow microfiltration (MF) and ultrafiltration (UF) experiments of limed mixed juice to $\mathrm{pH}$ of 7.5 were carried out in plate and frame module employing polysulphone membranes. The experimental study was carried out to examine the effect of membrane molecular weight (MWCO) and the transmembrane pressure (TMP) on the membrane fouling characteristics and flux decline behavior. A comparative analysis using one MF (GRM0.1PP MF) membrane and one UF (GR40PP UF) membrane was done at different TMP (viz. 1.0, 1.5 and 2.0 bar). Three theoretical models viz. cake filtration model, internal pore blocking model, and complete pore blocking model were used to predict the membrane resistances and permeate flux. The models were used further to help in the analysis and to isolate a suitable membrane among the studied one with respect to flux and resistance.

\section{MEMBRANE FOULING}

The International Union of Pure and Applied Chemistry (IUPAC) defines fouling as; "the process resulting in loss of performance of a membrane due to deposition of 
suspended or dissolved substances on its external surfaces, at its pore openings, or within its pores" (Koros et al. [10] referenced by Roorda and van der Graaf [11]). For process engineers designing systems, Roorda and van der Graaf [11] classified fouling into essentially five mechanisms, as illustrated in Fig. 1, each monitored as a build of resistance $R_{x}$;

1. adsorption inside the membrane pores $\left(R_{a}\right)$,

2. blocking of the membrane pores $\left(R_{p}\right)$,

3. concentration of foulants near the membrane surface, also called concentration polarization $\left(R_{c p}\right)$,

4. deposition on the membrane surface forming a cake layer $\left(R_{c}\right)$ and

5. compression of the cake layer $\left(R_{c c}\right)$.
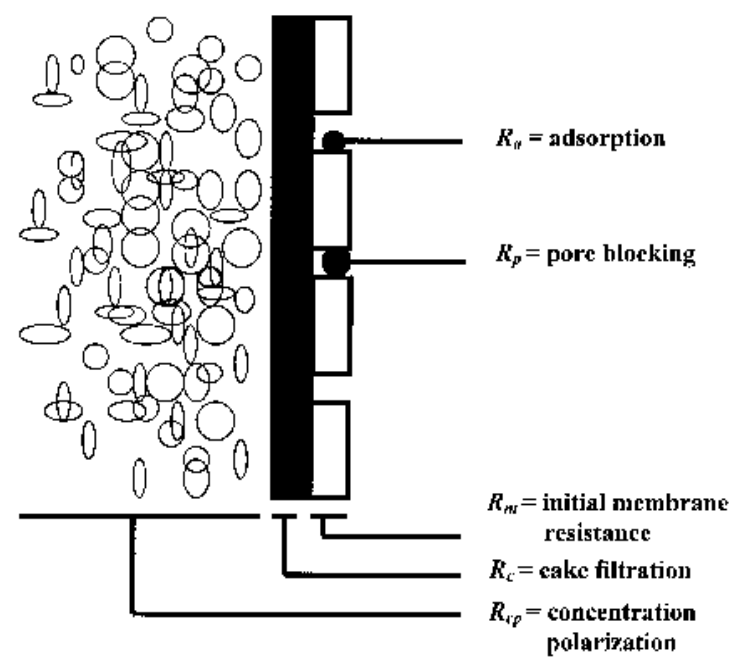

Fig. 1 Resistance of a fouled membrane contributed to various fouling mechanisms (Berg van den [12] referenced by Roorda and Graaf van der [11])

During filtration these mechanisms may occur simultaneously. The average pore diameter and the porosity of the membrane mainly determine the initial resistance of the membrane $\left(R_{\mathrm{m}}\right)$ [11]. Huang and Morrissey [6] suggest that fouling of membrane by both suspended and soluble proteinaceous matter in surimi wash water is a dynamic process starting with pore blocking at the initial stage of filtration, and followed by a continuous cake layer formation.

Hermia [13] referenced by Jacob and Jaffrin [14] derived four different filtration laws. The basis is Darcy's law, assuming homogeneous feed, spherical particles, cylindrical parallel homogeneous pores and every particle entering the membrane is stopped at or in the membrane matrix. The following filtration laws are defined for constant pressure dead-end filtration; complete pore blocking, cake filtration and internal pore blocking.

\subsection{Cake Filtration Model}

Particles, or macromolecules rejected by the membrane do not enter the pores; and form a cake on the membrane surface. The overall resistance is composed of a 
membrane resistance $R_{m}$ and a cake resistance $R_{c}$ [15]. The cake resistance increased proportionally to the amount of volume filtered $V_{f}$ or to the particle mass brought to the membrane by the filtration, thus, the total filtration resistance may be written [14];

$$
R_{t}=R_{m}+R_{c}=R_{m}+\frac{\alpha_{c} c_{m} V_{f}}{A_{o}}
$$

where $\alpha_{c}$ is the cake specific resistance per unit mass, $c_{m}$ is the rejected particle concentration near the membrane, and $A_{o}$ is the total membrane area. Thus, the permeate flow rate $Q_{f}$ is calculated as [14];

$$
Q_{f}=\frac{d V_{f}}{d t}=\frac{\Delta P A_{o}}{\mu\left(R_{m}+\frac{\alpha_{c} c_{m} V_{f}}{A_{o}}\right)}
$$

where $\mu$ is the permeate viscosity. Assuming that $R_{m}$ and $\alpha_{\mathrm{c}}$ and $c_{m}$ are constants, and integrating Eq. (2) gives;

$$
\frac{t}{V_{f}}=\frac{1}{Q_{o}}+\frac{\alpha_{c} c_{m} V_{f}}{2 A_{o} R_{m} Q_{o}}
$$

where $Q_{o}$ is the initial permeate flow rate at $t=0$ before the cake is formed and is calculated as;

$$
Q_{o}=\frac{\Delta P A_{o}}{\mu R_{m}}
$$

\subsection{Internal Pore Blocking (Progressive Internal Fouling)}

Particles or macromolecules enter the pores and either gets deposited or adsorbed reducing pore volume. The irregularity of pore passages causes the particle to become tightly fixed blinding the pore. In this case, membrane resistance increases as a consequence of pore size reduction. Besides, if internal pore blocking occurs, fouling becomes independent of cross flow velocity [15].

If $L_{m}$ denotes the membrane thickness and $N$ the total number of pores assumed to be cylindrical parallel homogeneous pores with uniform radius $r_{p}$, we can write [14];

$$
2 \pi N L_{m} r_{p} \frac{d r_{p}}{d t}=-C_{a} Q_{f}
$$

where $C_{a}$ is dimensionless parameter characterizing the fraction of solute which get adsorbed. Integrating of Eq. (5) with respect to time yields;

$$
\pi N L_{m}\left(r_{p o}^{2}-r_{p}^{2}\right)=C_{a} V_{f}
$$

where $r_{p o}$ is the initial pore radius. Using Poiseuille's law in the pores and substituting $r_{p}^{2}$ from Eq. (6), we obtain;

$$
Q_{f}=Q_{o}\left(1-\frac{C_{a} V_{f}}{V_{P}}\right)^{2}
$$

where $V_{p}$ is the total initial pore volume and is calculated as;

$$
V_{p}=\pi N r_{p o}^{2} L_{m}
$$

Integration of Eq. (7) with respect to time yields; 


$$
\frac{t}{V_{f}}=\frac{1}{Q_{o}}+\frac{C_{a} t}{V_{p}}
$$

\subsection{Complete Pore Blocking Model}

When particles are larger than pore size, the membrane portion of the filtration area reached by particles is blocked as a consequence of a complete pore obstruction by means of sealing (blocking) [15]. In this case the fractional area $A$ of the membrane decreases proportionally to the filtered volume [14];

$$
A=A_{o}-\sigma V_{f}
$$

where $\sigma$ is a parameter characterizing the plugging potential of the suspension, which can be expected to be proportional to the particle concentration. Here, the flux decay is assumed to be solely because of a reduction in membrane area and not due to an increase in resistance. Therefore, the permeate flux is given by;

$$
Q_{f}=Q_{o}\left(1-\frac{\sigma V_{f}}{A_{o}}\right)
$$

and by integration of Eq. (11) with respect to time;

$$
V_{f}=\frac{A_{o}}{\sigma}\left(1-\exp \left(-\sigma J_{o} t\right)\right)
$$

where $J_{o}$ is the initial permeate flux, and by substituting Eq. (12) into Eq. (11);

$$
Q_{f}=Q_{o} \exp \left(-\sigma J_{o} t\right)
$$

\section{EXPERIMENTAL METHODS AND MATERIALS}

The main aim of this study was to investigate the membrane fouling process in MF/UF clarification of the mixed juice. A test rig was designed and constructed at Sugar Technology Research Institute, Assiut University to serve this purpose. In order to reflect the real properties of mixed juice, this research was carried out on-site at the Pilot Plant for Sugar Research at the Qus Sugar Mill.

\subsection{Materials}

The feed to the test rig was either the hot fresh mixed juice or the clear juice. Mixed juice was collected from the sampler tank located after the mill house at Qus factory. The clear juice was obtained by adding the milk of lime to the mixed juice at a temperature of about $72{ }^{\circ} \mathrm{C}$ under constant stirring to increase the $\mathrm{pH}$ to the preset value.

Four organic flat sheet membranes of different pore size or MWCO were selected in the present study. They were obtained from Alfa Laval Nakskov A/S Company, Denmark and used without any further modification. The main characteristics of these membranes are given in Abbara [16]. Pre-filters were used to remove fibrous material and suspended solids that foul the membrane. 


\subsection{Experimental Set-Up}

The microfiltration and the ultrafiltration (MF/UF) experiments were carried out in a simple and flexible filtration system designed and assembled at the Sugar Technology Research Institute of Assiut University. The experimental set-up is shown in Fig. 2. Pre-filters and MF/UF module were arranged so that each component could operate alone or in series with the others. Pressure gauges were mounted at the inlet and outlet of pre-filters and the membrane module. The feed vessel and the receiving tank are equipped with stirrers of variable speeds and steam coils for heating. Level indicators and temperature sensors are also mounted.

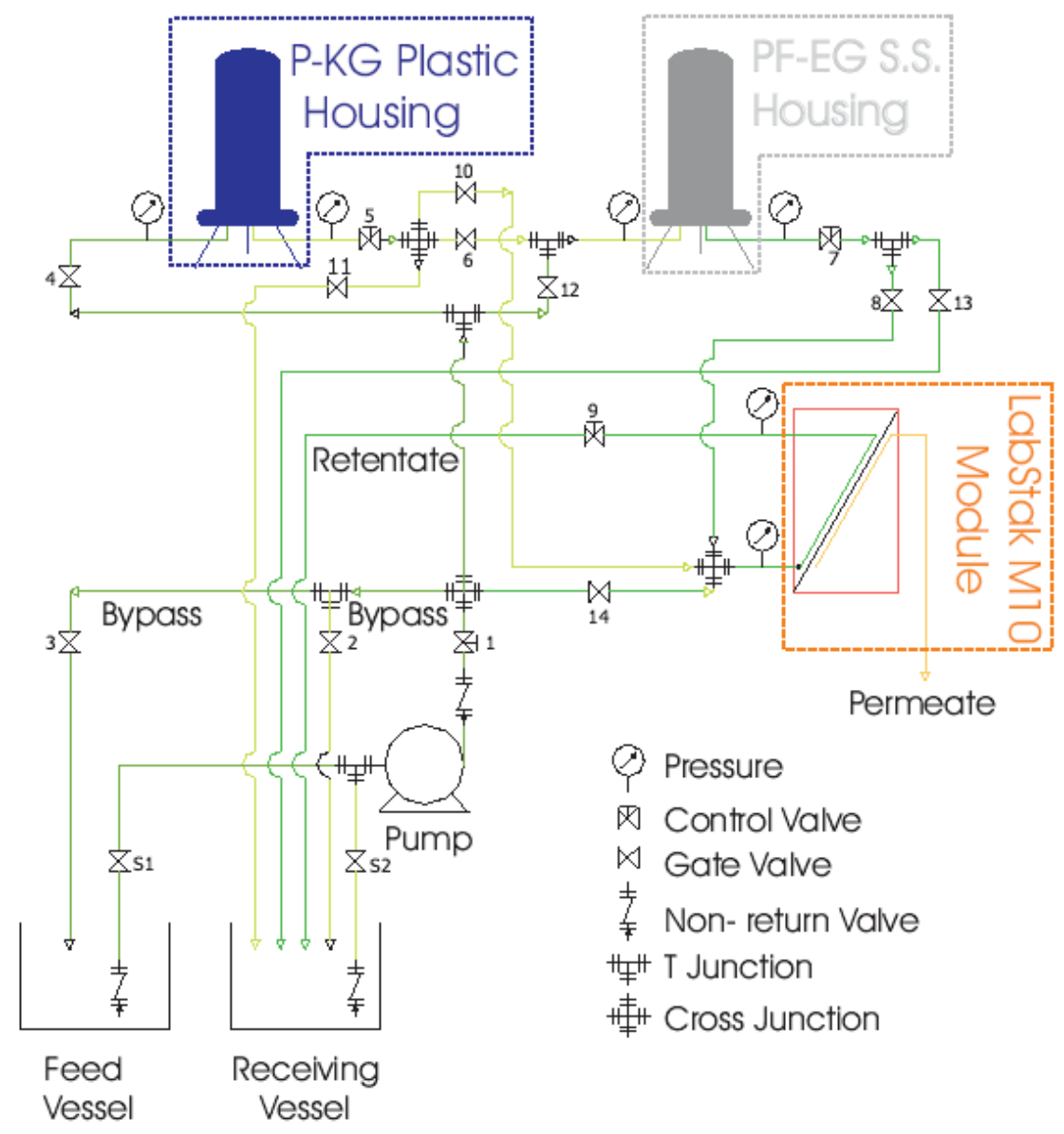

Fig. 2 Schematic flow diagram of the experimental set-up

The solution is pumped to the P-KG plastic prefilter in which an ultrapolydepth ${ }^{\circledR}$ PP-TF depth filter of $50 \mu \mathrm{m}$ is used to remove suspended particles prior to microfiltration and ultrafiltration is installed. The solution from the prefilter is either directed to the other prefilter with element of pore size less than the first one then to the membrane module, or to the receiving vessel. 


\subsection{Experimental Procedure and Analysis}

The experiments were designed to enable us to gather the necessary information with minimum cost. A group of experiments were planned to determine the membrane fouling characteristics and to examine the agreement of membrane filtration with different fouling models. These experiments were carried out using two types of membrane installed simultaneously on the membrane module. The membranes were of type: GRM0.1PP MF and GR40PP UF. The experiments were carried out at a temperature of $70{ }^{\circ} \mathrm{C}$ and at different TMP.

To determine the membrane fouling, the water flux was measured both before and after the cane juice membrane filtration at TMP of 0.85 bar and temperature of 60 ${ }^{\circ} \mathrm{C}$. The membrane fouling was calculated as a percentage drop in the water flux.

\section{RESULTS AND DISCUSSION}

The raw juice is a strong foulant because of the presence of objectionable amounts of proteins, polysaccharides, starches, gums and other non-sugars that constitute up to $2.5 \%$ of the juice $[17,18]$. Membrane fouling is affected by several factors such as filtration pretreatment, $\mathrm{pH}$, and transmembrane pressure.

Experiments were done to study the effect of transmembrane pressure on the fouling parameters of different classical fouling models during filtration of the mixed juice to $\mathrm{pH}$ of 7.5. Membranes of type GRM0.1PP MF and GR40PP UF were tested simultaneously. In each experiment, new membranes were used. Clear juice was prefiltered using $50 \mu \mathrm{m}$ filter element. The membrane filtration tests were done at constant temperature of $70{ }^{\circ} \mathrm{C}$. Figures 3 and 4 show experimental data for the permeate flux as a function of time during filtration of the limed juice at different TMP through GRM0.1PP MF and GR40PP UF, respectively. The initial flux of MF, as is shown in Fig. 3 increased with pressure, varying from almost $238 \mathrm{~L} / \mathrm{m}^{2} . \mathrm{h}$ at TMP of 2.0 bar to $111 \mathrm{~L} / \mathrm{m}^{2}$.h at TMP of $1.0 \mathrm{bar}$, consistence with the constant resistance of the clean membrane. The flux remained greater at the higher pressure throughout the filtration. After 90 min of filtration, the rate of flux decline was $29 \%$ at TMP of 1.0 bar, $31 \%$ at TMP of 1.5 bar and $25 \%$ at TMP of 2.0 bar. The figures show that the flux declines rather exponentially where the best fit equations are shown in the figures.

It is clear from Fig. 4 that the variation of the flux of filtering of the limed juice through the UF membrane against TMP has the same trend as of MF. Thus, the flux of the UF membrane is also increased with increasing the TMP. Figure 4 shows that the initial flux of UF decreases from nearly $198 \mathrm{~L} / \mathrm{m}^{2}$.h at TMP of 2.0 bar to about 91 $\mathrm{L} / \mathrm{m}^{2}$.h at TMP of 1.0 bar. At the end of the test, the rate of flux decay was $28.3 \%$, $26.9 \%$ and $28.5 \%$ at TMP of 1.0, 1.5 and 2.0 bar, respectively. As it is expected, the flux of MF membrane is higher than that of UF membrane at every respective TMP.

Figure 5 shows the experimental results for the total collected volume as a function of time during filtration of the limed juice through GRM0.1PP MF membrane at different TMP. It is clear from the figure that the permeate volume is slightly dependent on TMP at short times up to 10 minutes. After 10 minutes the total volume collected is increased with increasing transmembrane pressure. The permeate volume for the case with TMP $=2.0$ bar after 90 min of filtration is about $34.4 \%$ greater than that for the case at TMP of 1.5 bar. The latter was about $32.3 \%$ greater than for the run 
at TMP of 1.0 bar. Thus, the dependence of volume (L) on TMP was almost linear. Accordingly, these membranes were incompressible at the pressures used in these experiments.

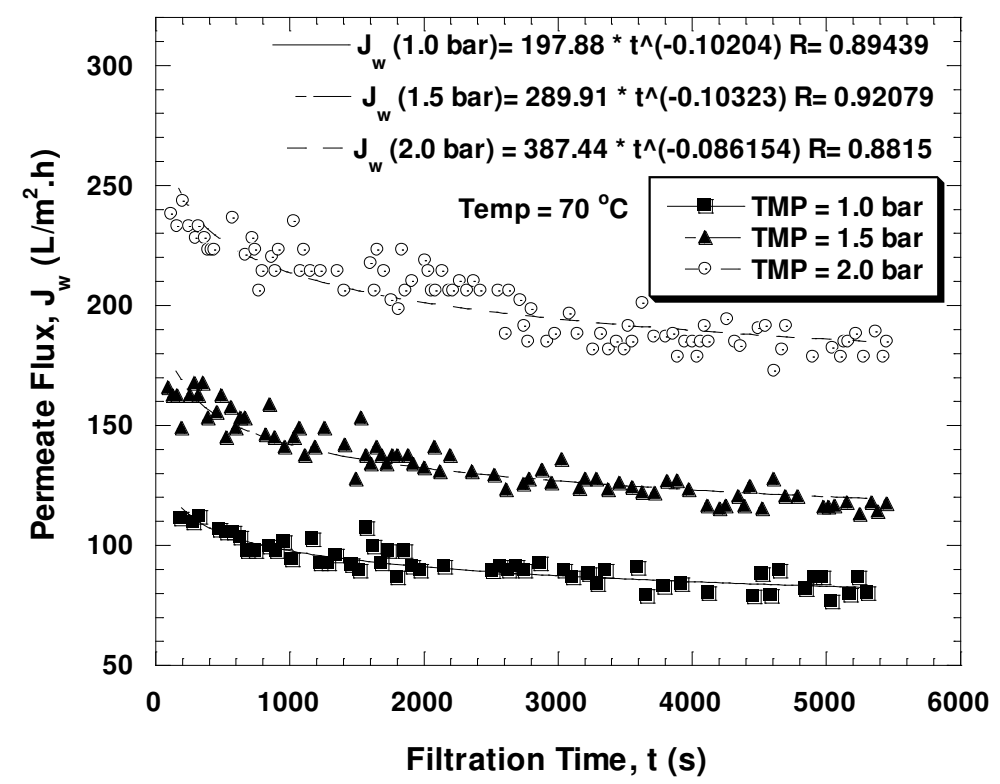

Fig. 3 Effect of transmembrane pressure on the permeate flux during filtration of limed juice through GRM0.1PP MF

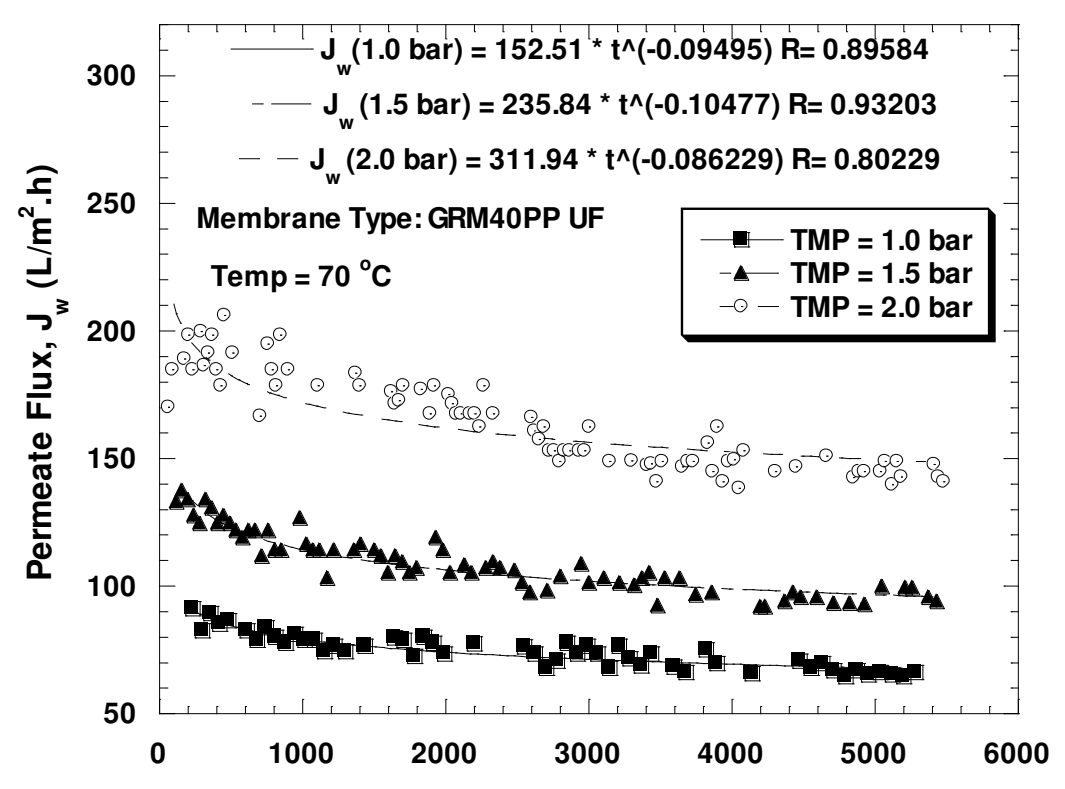

Filtration Time, $\mathbf{t}(\mathbf{s})$

Fig. 4 Effect of transmembrane pressure on the permeate flux during filtration of limed juice through GR40PP UF 


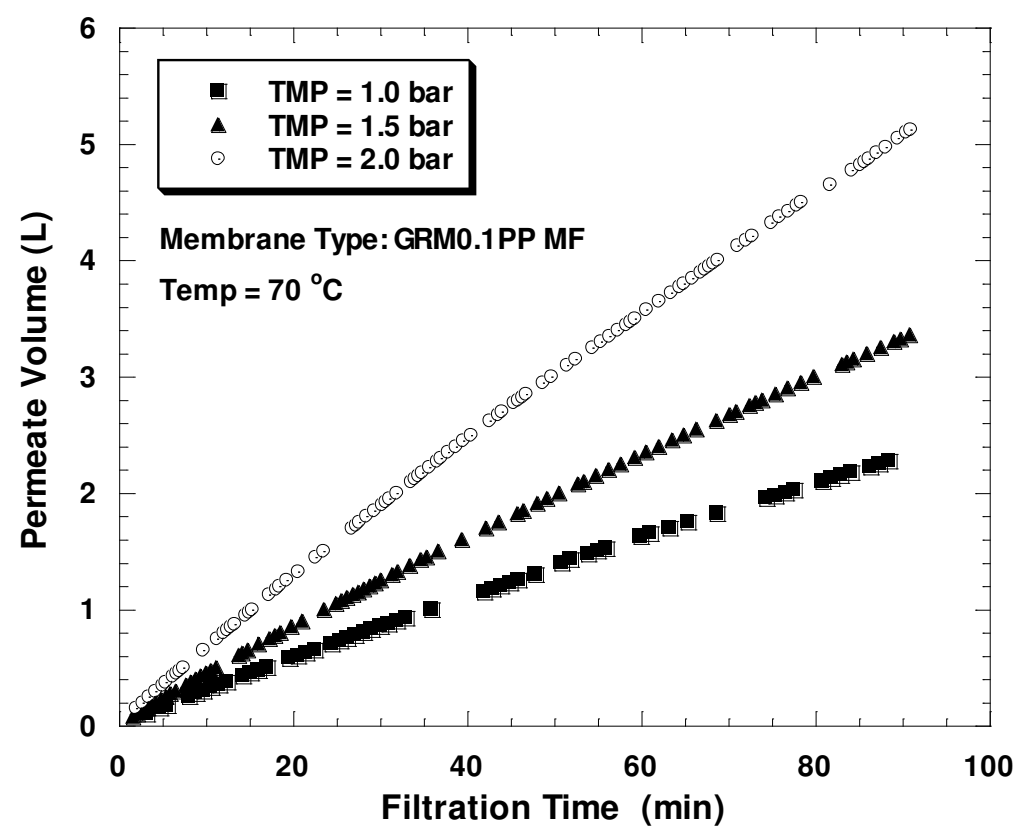

Fig. 5 Effect of transmembrane pressure on the permeate volume during filtration of limed juice through GRM0.1PP MF

In a similar way, Fig. 6 shows that the total collected volumes of UF permeate as a function of time for the different values of TMP is slightly dependent on TMP at short times (about 10 minutes). After 10 minutes, the total volume increases with increasing the transmembrane pressure. The total UF permeates collected after $90 \mathrm{~min}$ of filtration time are $1.800 \mathrm{~L}, 2.675 \mathrm{~L}$ and $4.1 \mathrm{~L}$ at TMP of $1.0 \mathrm{bar}, 1.5 \mathrm{bar}, 2.0 \mathrm{bar}$; respectively. These values are smaller than that of MF permeate at a specified TMP. This is consistent with the flux data shown in Figs. 3 and 4.

The membrane fouling calculated as the percentage drop of clean water volume flow rate before and after filtration run of the MF was $60.5 \%$ at TMP of 1.0 bar, $44.5 \%$ at TMP of 1.5 bar and $57.9 \%$ at TMP of 2.0 bar. The same parameter (membrane fouling) of the UF was 56.0\%, 35.7\% and $44.2 \%$ at TMP of 1.0, 1.5 and 2.0 bar, respectively. Both types of the studied membranes have a high fouling rate regardless of the TMP. This is consistent with our previous finding as reported by Abbara et al. [19], where the highest fouling rate was shown after the first experiment.

The long-term flux decline due to fouling may be predicted by [20]

$$
J_{w}(t)=J_{2} t^{-f_{c}}
$$

where $J_{2}$ is the permeate flux at the onset of quasi-state operation, $t$ is the filtration time, and $f_{c}$ is the fouling rate constant. At higher $f_{c}$, the flux is declined more rapidly. Kim et al. [20] reported that the fouling rate constant $f_{c}$ varies from 0.2 to 0.8 for yeast cells when $J_{w}(t)$ is given in $\mathrm{L} / \mathrm{m}^{2}$.h and $t$ in seconds.

In Figs. 3 and 4 the solid lines represent fitting flux data versus time according to the Eq. (14). The results of both MF and UF are in good agreement with the model. The fouling rate constants, $f_{c}$, at different TMP of MF are 0.102, 0.103 and 0.086 at 
TMP of 1.0, 1.5 and 2.0 bar, respectively. The fouling rate constant $f_{c}$ at TMP of 1.0 bar is almost the same as its counterpart at TMP of 1.5 bar which means that the rate of flux decline is nearly the same at both of these TMP. The fouling rate constants, $f_{c}$, at different TMP of UF are 0.094, 0.105 and 0.086 at TMP of 1.0, 1.5 and 2.0 bar, respectively. At a certain TMP the fouling constant rates of both the MF and UF are almost identical.

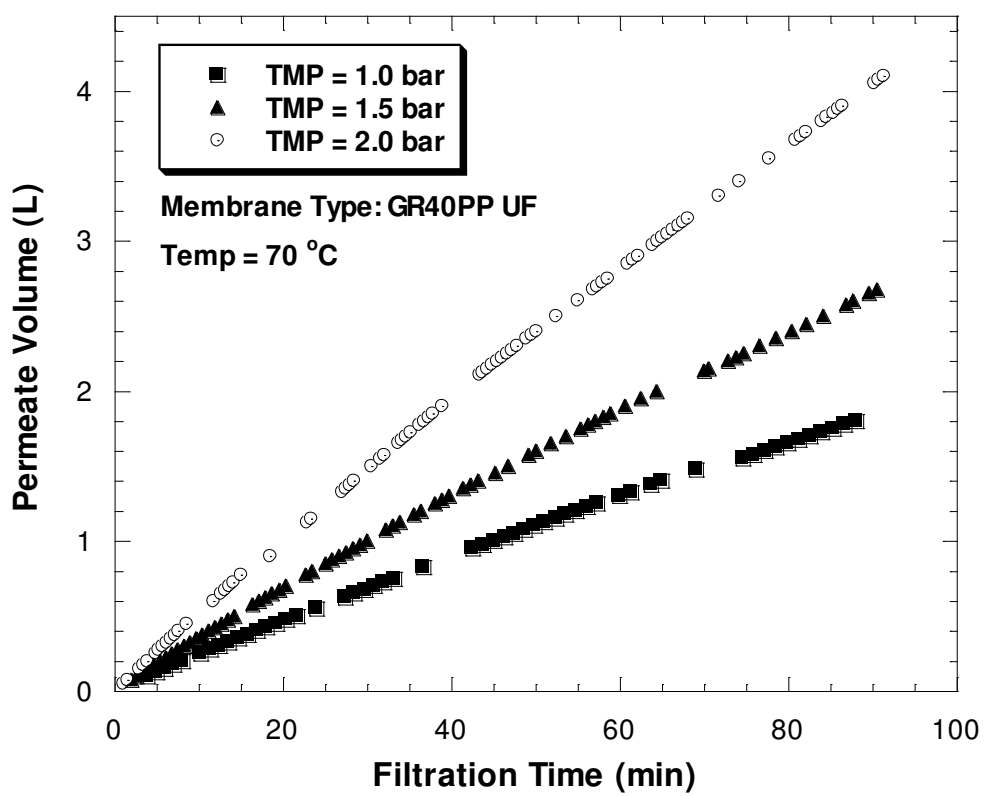

Fig. 6 Effect of transmembrane pressure on the permeate volume during filtration of limed juice through GR40PP UF

Another method to estimate the membrane fouling is to plot the total hydraulic resistance $R_{t}$ according to Darcy's law [21]. Thus;

$$
R_{t}=\frac{\Delta P}{\mu \cdot J}
$$

where $\mu$ is the dynamic viscosity of sugar solution (Pa. s) and $J$ is the flux $(\mathrm{m} / \mathrm{s})$.

A plot of the total hydraulic resistance against filtration time permits the comparison of the fouling intensity at different pressures. Fouling rate $\left(\alpha_{f}\right)$ is quantified using two slopes obtained from the curves plotted for $R_{t}$ vs. time; $\alpha_{o}$ and $\alpha_{s}$ defined as the sloping at the beginning and during the linear final phase (pseudo-steady state phase), respectively. These slops are calculated by simple linear regression [21].

The variation of the total resistance $R_{t}$ of the MF membrane and UF membrane are plotted as a function of time in Figs. 7 and 8, respectively. As shown, the resistance at TMP of 2.0 bar was the lowest which is consistent with the highest flux. In attempt to make the variation of the resistance with TMP more visible, the total resistance is plotted as a function of filtered dissolved solid mass (the product of permeate volume by volume Brix) as is shown in Figs. 9 and 10. Figure 9 illustrates that the rate of increasing resistance with the total dissolved mass filtered through the membrane is almost the same at TMP of 1.0 and 1.5 bar and both resistances are almost the same. 
However the rate of increasing the resistance at TMP of 2.0 bar is different and we can say it nearly reaches the pseudo-steady state phase. The same behavior is also noticed for the UF membrane as is shown in Fig. 10.

Fitting the data of Fig. 7 by linear regression, the rate of fouling estimated as the slope $\alpha_{s}$ is $2.054 \times 10^{10}, 2.718 \times 10^{10}$ and $1.859 \times 10^{10} \mathrm{~m}^{-1} \cdot \mathrm{min}^{-1}$ at TMP of $1.0,1.5$ and 2.0 bar, respectively. The slope $\alpha_{s}$ of UF membrane, calculated based on fitting the data of Fig. 8 by linear regression is $2.437 \times 10^{10}, 3.259 \times 10^{10}$ and $2.807 \times 10^{10} \mathrm{~m}^{-}$ ${ }^{1} . \mathrm{min}^{-1}$ at TMP of 1.0, 1.5 and $2.0 \mathrm{bar}$, respectively. The slope $\alpha_{\mathrm{s}}$ at a certain TMP of UF membrane is higher than that of the MF membrane. However, a surprising result is the resistance at the TMP of 1.5 bar is higher than the résistance at the TMP of $2.0 \mathrm{bar}$ of both MF and UF, which in turn reflected on $\alpha_{s}$. A physical explanation for this behavior is not available, but it could be due to a possible mistake in the membrane specifications. The final observation is consistent with the fouling constant rate $f_{c}$ where the $f_{c}$ value is also higher at TMP of 1.5 than at TMP of 1.0 bar.

The traditional approach to examine the fouling mechanism is to plot the filtrate flux data in an appropriate linearized form developed by rearranging the expressions for the complete pore blocking, internal pore blocking and cake filtration models. To check the applicability of cake filtration model (Eq. (3)) on the microfiltration and ultrafiltration experiments, the variation of $t / V_{f}$ versus $V_{f}$ for the data of Figs. 3 and 4 at different TMP are shown in Figs. 11 and 12, respectively. As it is shown in Figs. 11 and 12, the experimental data are in a very good agreement with the cake filtration model with a correlation coefficient of both MF and UF listed in Table 1.

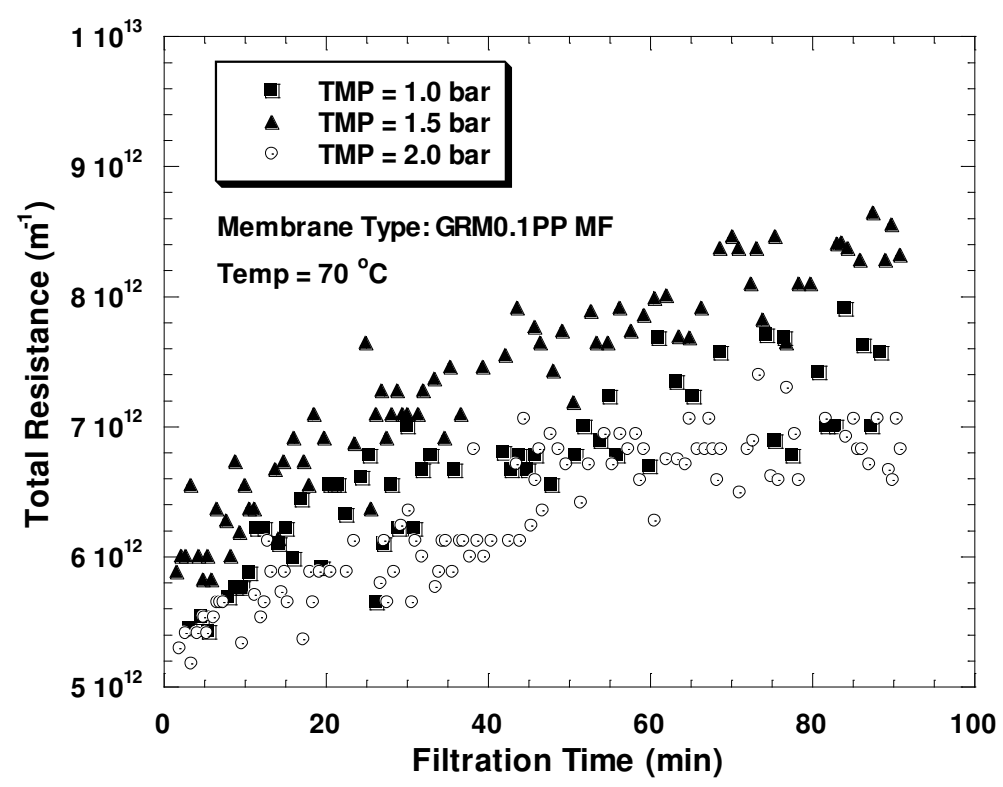

Fig. 7 Total hydraulic resistances, $R_{t}$, versus filtration time for filtering the limed juice through GRM0.1PP MF at temperature of $70{ }^{\circ} \mathrm{C}$ and at different transmembrane pressure 


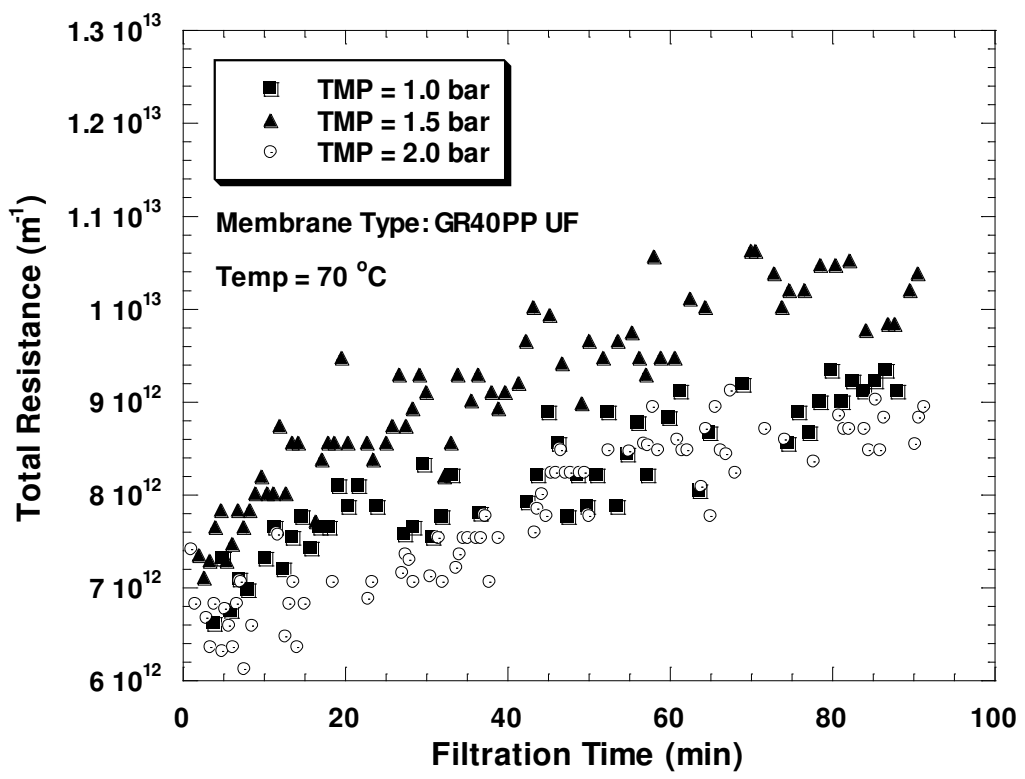

Fig. 8 Total hydraulic resistances, $R_{t}$, versus filtration time for filtering the limed juice through GR40PP UF at temperature of $70{ }^{\circ} \mathrm{C}$ and at different transmembrane pressure

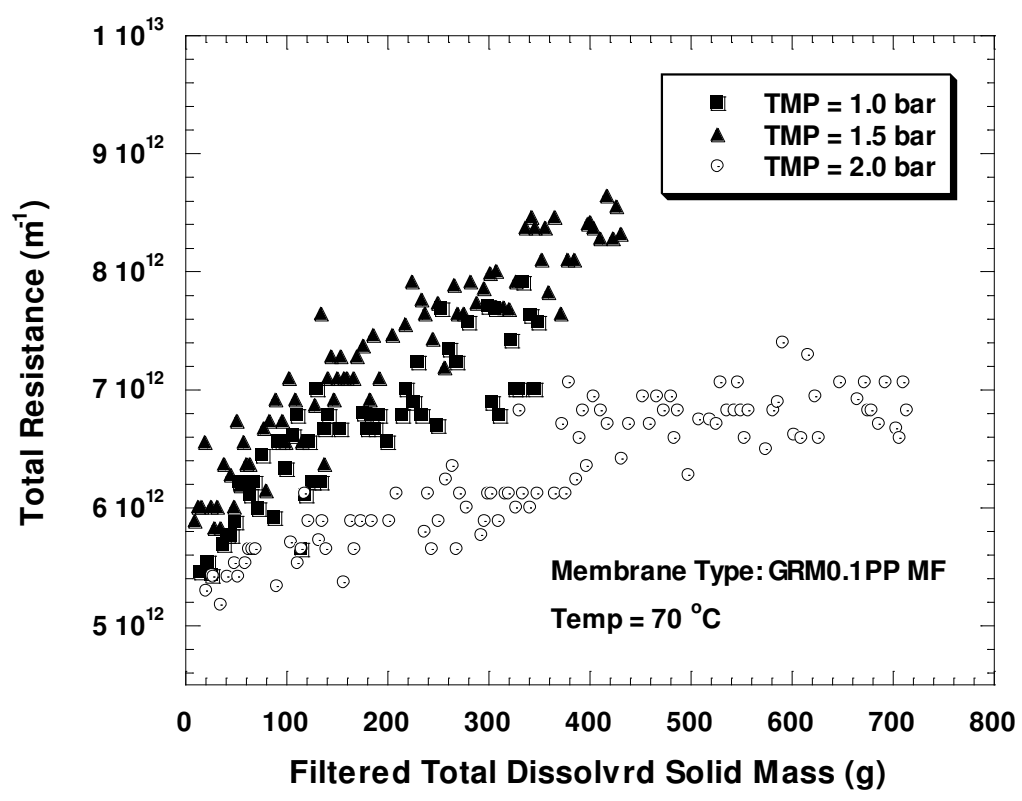

Fig. 9 Total hydraulic resistances, $R_{t}$, versus filtered total dissolved mass solids for filtering the limed juice through GRM0.1PP MF at temperature of $70{ }^{\circ} \mathrm{C}$ and at different transmembrane pressure 


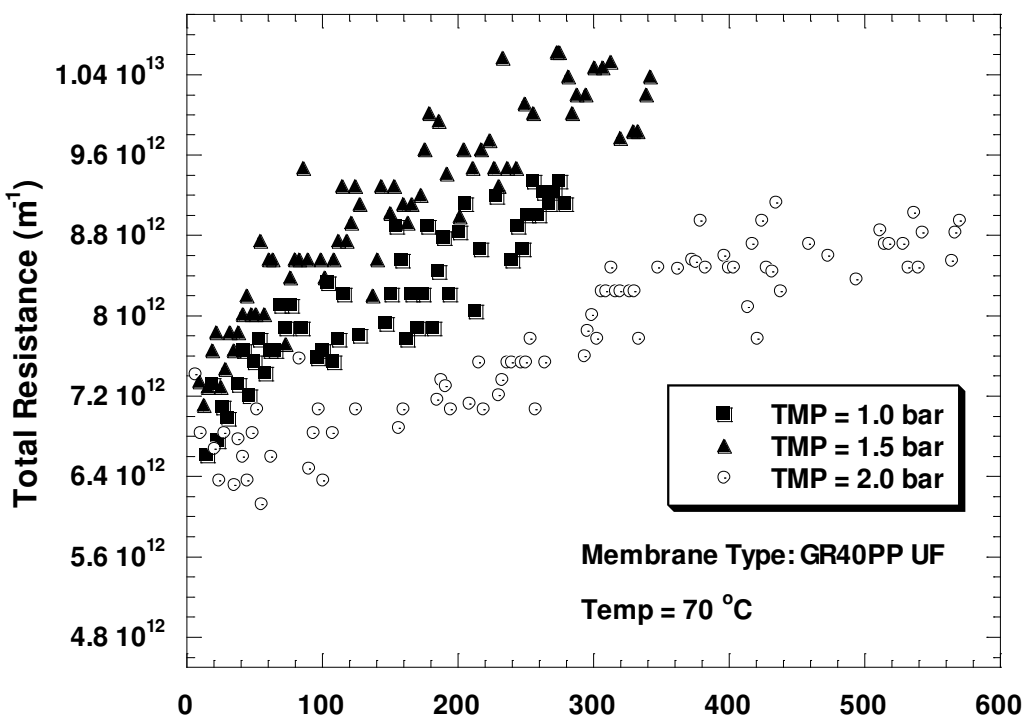

Filtered Total Dissolvrd Solid Mass (g)

Fig. 10 Total hydraulic resistances, $R_{t}$, versus filtered total dissolved mass solids of the limed juice filtered through GR40PP UF at temperature of $70{ }^{\circ} \mathrm{C}$ and at different transmembrane pressure

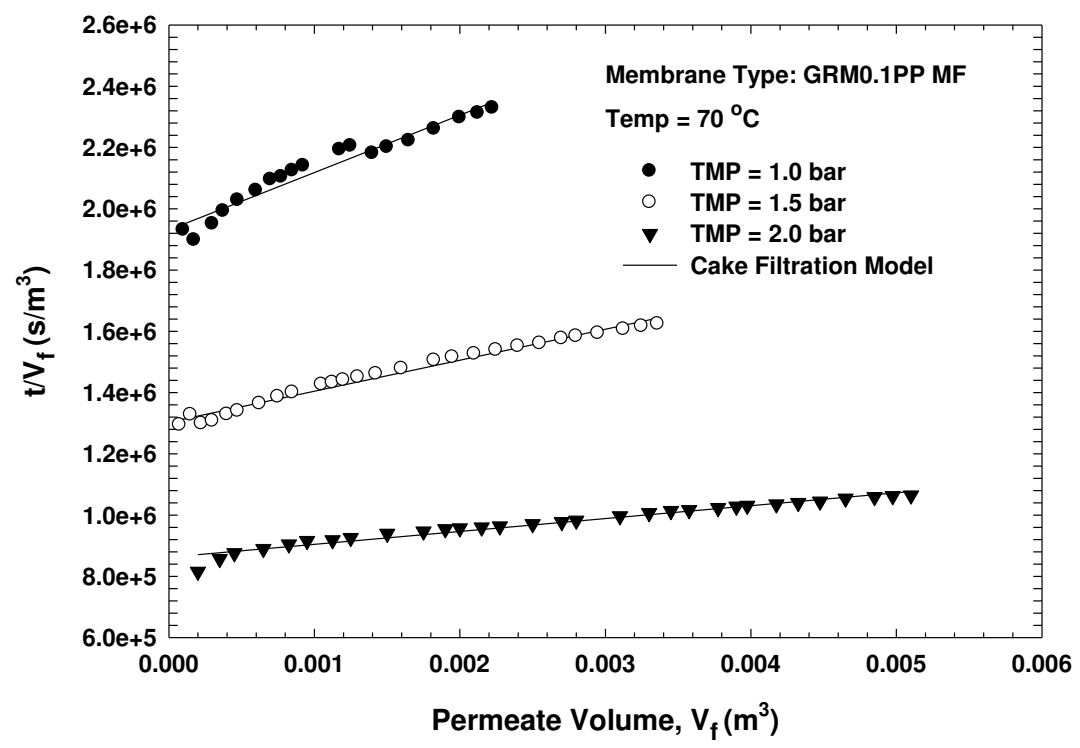

Fig. 11 Filtration curve, $t / V_{f}$, versus $V_{f}$ measured at different values of transmembrane pressure using membrane type: GRM0.1PP MF

It is concluded from Table 1 that the values of $\alpha_{c} c_{m}$ decreases with increasing the transmembrane pressure for both MF and UF membrane. Moreover, these values for MF are smaller than those of UF at the respective TMP. As it is expected, the initial 
flux increases with increasing TMP and its value for UF is less than that of MF at the respective TMP.

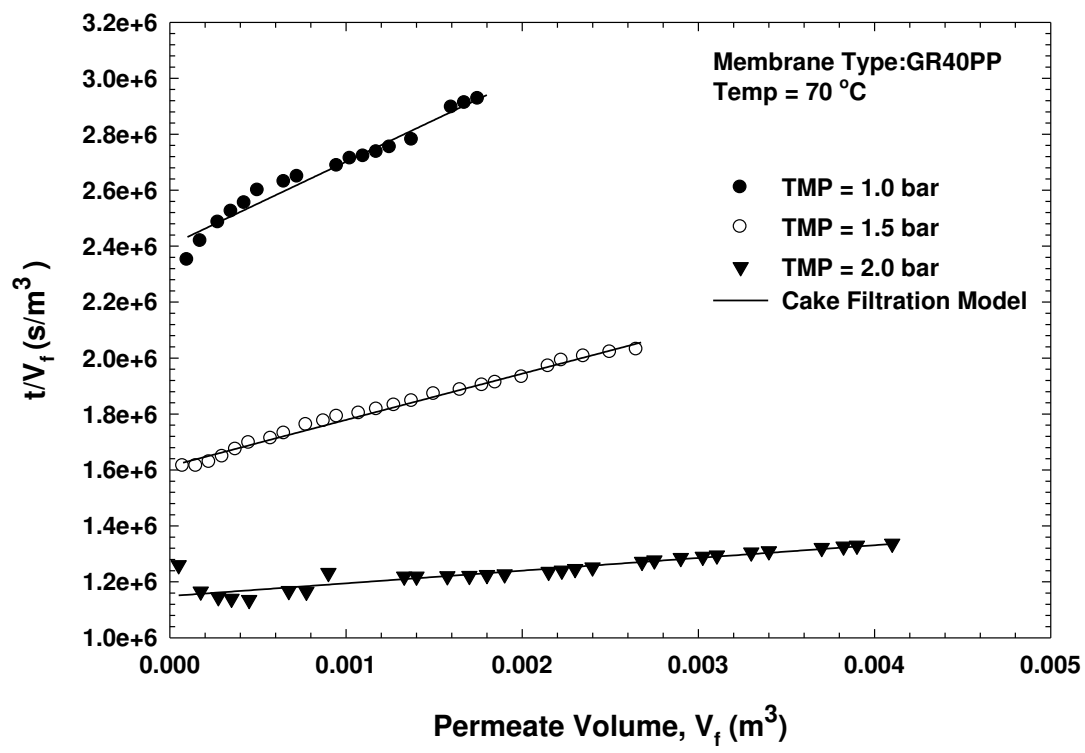

Fig. 12 Filtration curve, $t / V_{f}$, versus $V_{f}$ measured at different values of transmembrane pressure using membrane type: GR40PP UF

The variation of $t / V_{f}$ versus time for the MF data is plotted in Fig. 3. In the same manner, Fig. 14 represents the variation of $t / V_{f}$ versus time for the UF data. This is done in order to check the agreement of MF and UF data with the pore narrowing model represented by Eq. (9). The fit with the pore narrowing model is as good as the cake filtration model for both the MF and UF data. The values of $C_{a} / V_{p}$ and the correlation coefficient at different TMP are given in Table 2.

It is noticed from Table 2 that the values of $C_{a} / V_{p}$ decreases with increasing the transmembrane pressure. Furthermore, the $C_{a} / V_{p}$ values of MF are less than that of UF at a specified TMP, except for these values at TMP of 2.0 bar. The initial flux values, $J_{o}$, estimated by the pore narrowing model are close to those evaluated by cake filtration model.

Table 1 Determination of parameter $\alpha_{c} c_{m}$ and correlation coefficient $r$, for the cake filtration model for filtering the limed juice through GRM0.1PP MF and GR40PP UF at different TMP and at temperature of $70^{\circ} \mathrm{C}$

\begin{tabular}{|c|c|c|c|c|c|}
\hline $\begin{array}{c}\text { TMP } \\
(\mathbf{b a r})\end{array}$ & Membrane Type & $\begin{array}{c}\text { Time Interval } \\
(\mathbf{m i n})\end{array}$ & $\begin{array}{c}\boldsymbol{J}_{\boldsymbol{o}} \\
\left(\mathbf{L} / \mathbf{m}^{\mathbf{2}} \mathbf{h}\right)\end{array}$ & $\begin{array}{c}\boldsymbol{\alpha}_{\boldsymbol{c}} \boldsymbol{c}_{\boldsymbol{m}} \boldsymbol{x} \mathbf{1 0}^{-\mathbf{1 3}} \\
\left(\mathbf{m}^{\mathbf{2}}\right)\end{array}$ & $\boldsymbol{r}$ \\
\hline 1.0 & GRM0.1PP MF & $3.5-90$ & 111 & 1.78 & 0.974 \\
\hline 1.5 & GRM0.1PP MF & $3.5-90$ & 164 & 1.55 & 0.991 \\
\hline 2.0 & GRM0.1PP MF & $3.5-90$ & 249 & 8.33 & 0.974 \\
\hline 1.0 & GR40PP UF & $3.5-90$ & 89 & 2.82 & 0.986 \\
\hline 1.5 & GR40PP UF & $3.5-90$ & 133 & 2.53 & 0.994 \\
\hline 2.0 & GR40PP UF & $3.5-90$ & 186 & 0.898 & 0.945 \\
\hline
\end{tabular}


Table 2 Determination of parameter $C_{a} / V_{p}$ and correlation coefficient $r$, for the pore narrowing model for filtering the limed juice through GRM0.1PP MF and GR40PP UF at different TMP and at Temperature of $70^{\circ} \mathrm{C}$

\begin{tabular}{|c|c|c|c|c|c|}
\hline $\begin{array}{c}\text { TMP } \\
(\mathbf{b a r})\end{array}$ & Membrane Type & $\begin{array}{c}\text { Time Interval } \\
(\mathbf{m i n})\end{array}$ & $\boldsymbol{J}_{\boldsymbol{o}}\left(\mathbf{L} / \mathbf{m}^{2} \cdot \mathbf{h}\right)$ & $\begin{array}{c}\boldsymbol{C}_{\boldsymbol{a}} / \boldsymbol{V}_{\boldsymbol{p}}\left(\mathbf{m}^{-}\right. \\
\mathbf{3})\end{array}$ & $\boldsymbol{r}$ \\
\hline 1.0 & GRM0.1PP MF & $3.5-90$ & 110 & 77 & 0.969 \\
\hline 1.5 & GRM0.1PP MF & $3.5-90$ & 163 & 62 & 0.986 \\
\hline 2.0 & GRM0.1PP MF & $3.5-90$ & 244 & 37 & 0.987 \\
\hline 1.0 & GR40PP UF & $3.5-90$ & 89 & 102 & 0.984 \\
\hline 1.5 & GR40PP UF & $3.5-90$ & 132 & 81 & 0.990 \\
\hline 2.0 & GR40PP UF & $3.5-90$ & 186 & 34 & 0.949 \\
\hline
\end{tabular}

The complete pore blocking model, which postulates that the flux decay is solely due to reduction in membrane area and not to the increase in resistance, is also compared with the MF data of Fig. 3 and the UF data of Fig. 4. Data were fitted according to the Eq. (13). The results according to this model are given in Table 3. It appears from Table 3 that the value of $\sigma$, which is a parameter characterizing plugging potential of suspension, decreases with increasing the transmembrane pressure. Moreover, at any TMP the $\sigma$ value of UF are higher than that of the MF. However, this model gives the worst correlation coefficient among the other classical fouling models discussed before.

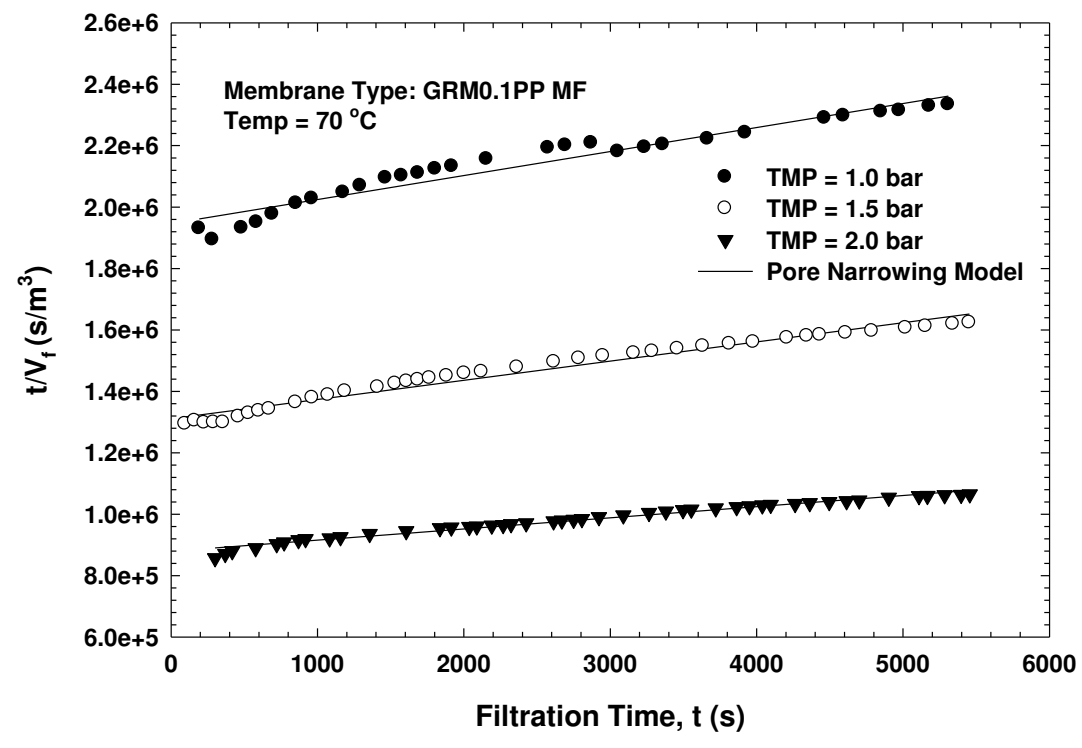

Fig. 13 Filtration curve, $t / V_{f}$, versus filtration time, $t$, measured at different constant TMP and at temperature of $70{ }^{\circ} \mathrm{C}$ using GRM0.1PP MF 


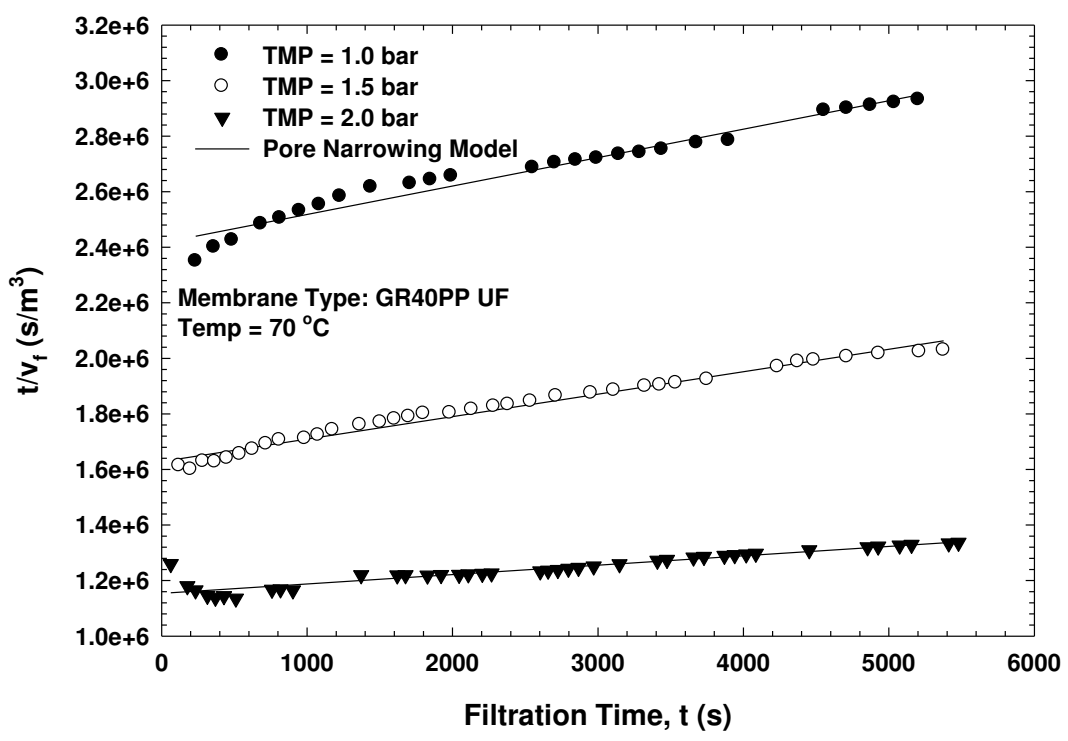

Fig. 14 Filtration curve, $t / V_{f}$, versus filtration time, $t$, measured at different constant TMP and at temperature of $70{ }^{\circ} \mathrm{C}$ using GR40PP UF

Table 3 Determination of parameter $\sigma$ and correlation coefficient $r$, for the complete pore blocking model for filtering the limed Juice through GRM0.1PP MF and GR40PP at different TMP and at temperature of $70^{\circ} \mathrm{C}$

\begin{tabular}{|c|c|c|c|c|c|}
\hline $\begin{array}{c}\text { TMP } \\
(\text { bar })\end{array}$ & Membrane Type & $\begin{array}{c}\text { Time Interval } \\
(\mathbf{m i n})\end{array}$ & $\boldsymbol{J}_{\boldsymbol{o}}\left(\mathbf{L} / \mathbf{m}^{2} \cdot \mathbf{h}\right)$ & $\boldsymbol{\sigma}\left(\mathbf{m}^{-\mathbf{2}}\right)$ & $\boldsymbol{r}$ \\
\hline 1.0 & GRM0.1PP MF & $3.5-90$ & 104 & 1.79 & 0.860 \\
\hline 1.5 & GRM0.1PP MF & $3.5-90$ & 158 & 1.48 & 0.907 \\
\hline 2.0 & GRM0.1PP MF & $3.5-90$ & 229 & 0.78 & 0.887 \\
\hline 1.0 & GR40PP UF & $3.5-90$ & 84 & 2.13 & 0.889 \\
\hline 1.5 & GR40PP UF & $3.5-90$ & 125 & 1.75 & 0.897 \\
\hline 2.0 & GR40PP UF & $3.5-90$ & 191 & 1.15 & 0.910 \\
\hline
\end{tabular}

\section{CONCLUSIONS AND RECOMMENDATIONS}

This work presents an on-site assessment of polymeric membrane plate modules for microfiltration and ultrafiltration of sugarcane juice on a laboratory-scale level to examine the mechanisms of the membrane fouling process. A test rig employs a DSS Labstak® M10 module was designed and constructed at the Sugar Technology Research Institute. Trials were done in Qus pilot plant at Qus Sugar Mill, Qena, Egypt using a fresh mixed juice.

Filtering the limed mixed juice through the two membranes (GRM0.1PP MF, and GR40PP UF) at different values of transmembrane pressure led to the following conclusions:

- Increasing transmembrane pressure within the examined range increases the permeate flux. 
- It was noticed that in all cases the membrane fouling was the highest at the first period of operation.

- Study of the mechanisms responsible for flux decline in MF and UF of limed mixed juice suggested that the membrane fouling is in good correlation with the cake filtration model and the pore narrowing model for both the GRM0.1PP MF and GR40PP UF.

- GRM0.1PP and GR40PP are proper choice of MF and UF membrane for clarification the limed juice. The final choice depends on the quality of the final product.

- It is possible to add another option to the range of solutions, which could be adopted in trying to eliminate the conventional sulphitation process.

\section{REFERENCES}

1. Godshall, M. A., Iqbal, K., Moore, S. and Triche, R.(1999). Potential new product development using membranes. Proc. of the Sugar Processing Research Institute, Inc., Symposium on Advanced Technology for Cane and Beet Refined Sugar Production, New Orleans, LA, USA, (C-11), (Abstract).

2. Balakrishnan, M., Dua, M. and Bhagat, J. J. (2000). Effect of operating parameters on sugarcane juice ultrafiltration: results of a field experience. Separation and Purification Technology, Vol. 19, pp. 209-220.

3. Madsen, R. F., Nielsen, W. K. and Kristensen, S. (1982). Purifying sugar juice. GB Patent, No. 2090861 A.

4. Song, L. (1998). Flux decline in crossflow microfiltration and ultrafiltration: mechanisms and modeling of membrane fouling. Journal of Membrane Science, Vol. 139, pp. 183-200.

5. Davis, R. H. (1992). Modeling of fouling of crossflow microfiltration membranes. Seperation and Purification Methods, Vol. 21, pp. 75-126.

6. Huang, L. and Morrissey, M. T. (1998). Fouling of membranes during microfiltration of surimi wash water: roles of pore blocking and surface cake formation. Journal of Membrane Science, Vol. 144, pp. 113-123.

7. Wang, L. and Song, L. (1999). Flux decline in crossflow microfiltration and ultrafiltration: experimental verification of fouling dynamics. Journal of Membrane Science, Vol. 160, pp. 41-50.

8. Chen, K. L., Song, L., Ong, S. L. and Ng, W. J. (2004). The development of membrane fouling in full-scale RO processes. Journal of Membrane Science, Vol. 232, pp. 63-72.

9. Mohammadi, T., Kohpeyma, A. and Sadrzadeh, M. (2005). Mathematical modeling of flux decline in ultrafiltration. Desalination, vol. 184, pp. 367-375.

10. Koros, W. J., Ma, Y. H. and Shimizu, T. (for: International Union of Pure and Applied Chemistry (IUPAC)) (1996). Terminology for membrane and membrane processes - IUPAC recommendations 1996. Journal of Membrane Science, Vol. 120, pp. 149-159.

11. Roorda, J. H. and Graaf, J. H. J. M. van der (2001). New parameter for monitoring during ultrafiltration of WWTP effluent. Water Science and Technology, Vol. 43, pp. 241-248. 
12. Berg, G. van den (1998). Concentration polarization in ultrafiltration models and experiments, PhD thesis, Department of Macromolecular Chemistry and Materials, Twente University.

13. Hermia, J. (1982). Constant pressure blocking filtration laws. Application to power- law non-Newtonian fluids. Trans. Inst. Chem. Eng., Vol. 60, pp. 183187.

14. Jacob, S. and Jaffrin, M. Y. (2000). Purification of brown cane sugar solutions by ultrafiltration with ceramic membranes: investigation of membrane fouling. Separation Science and Technology, Vol. 35, pp. 989-1010.

15. Barros, S. T. D. de, Andrade, C. M. G., Mendes, E. S. and Peres, L. (2003). Study of fouling mechanism in pineapple juice clarification by ultrafiltration. Journal of Membrane Science, Vol. 215, pp. 213-224.

16. Abbara, A. A. (2005). Study of using membrane filtration in clarification of sugar juices, PhD Thesis, Sugar Technology Research Institute, Assiut University, Assiut, Egypt.

17. Ghosh, A. M., Balakrishnan, M., Dua, M. and Bhagat, J. J. (2000). Ultrafiltration of sugarcane juice with spiral wound modules: on-site pilot trials. Journal of Membrane Science, Vol. 174, pp. 205-216.

18. Ghosh, A. M. and Balakrishnan, M. (2003). Pilot demonstration of sugarcane juice ultrafiltration in an Indian sugar factory. Journal of Food Engineering, Vol. 58, pp. 143-150.

19. Abbara, A.A., Ali K. Abdel-Rahman and Bayoumi, M. R. (2004). Production of white sugar using membrane technology. Proceedings of the International Mechanical Engineering Conference IMEC2004, Kuwait, Kuwait, pp. 5-8.

20. Kim, J., Akeprathumchai, S. and Wickramasinghe, S. R. (2001). Flocculation to enhance microfiltration. Journal of Membrane Science, Vol. 182, pp. 161172.

21. Dornier, M., Decloux, M., Lebert, A. and Trystram, G. (1994). Use of experimental design to establish optimal crossflow filtration conditions: application to raw cane sugar clarification. Journal of Food Process Engineering, Vol. 17, pp. 73-92. 


\section{الترشيح بالأغثية في صناعة السكر - انسداد الأغثية}

\section{د. على كامل عبد الرحمن ، د. عبد العزيز عبارة و أ.د. محمد رجب بيومي}

أجريت تجـارب عمليـة على عمليـات تتقيـة عصبير قصب السكر المجيـر إلى أس هيدروجيني 7.5

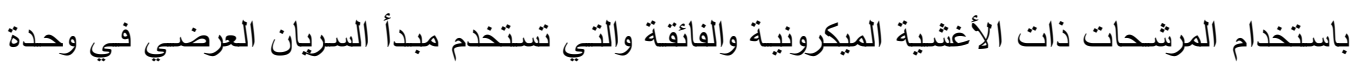
مسطحة ذات أغثية مصنوعة من مادة البولي صلفون. أجريت التجارب العملية بهدف اختبار تأثير كل

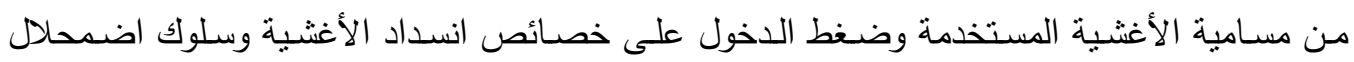

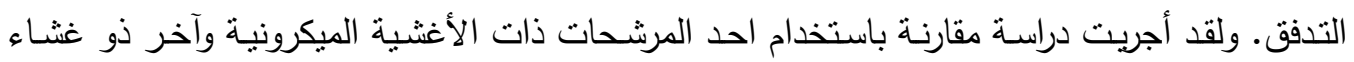

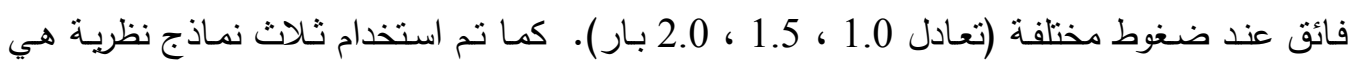

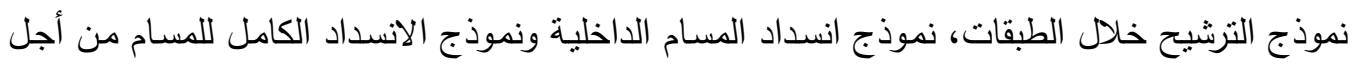

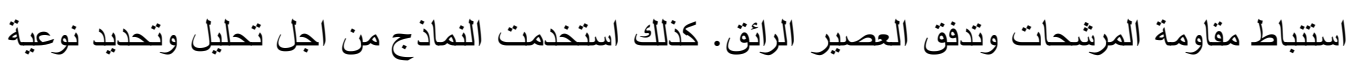

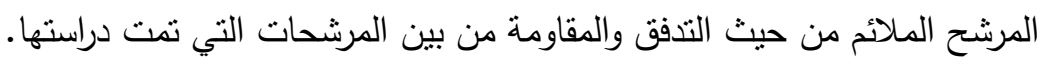

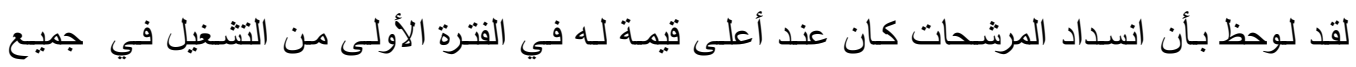

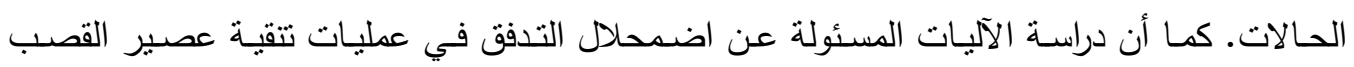

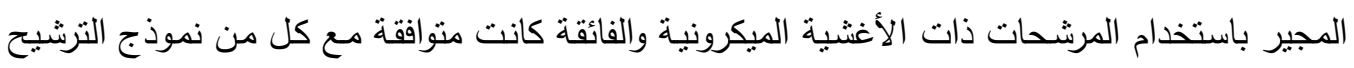

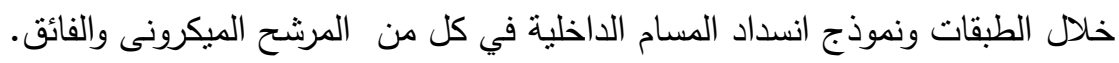

